\title{
Behavior of Polymer Films and its Blends for Leather Finishing
}

\author{
Cristiana Winter, Caroline Borges Agustini*, Márcia Elizabeth RS and Mariliz Gutterres \\ Department of Chemical Engineering, Federal University of Rio Grande doSul (UFRGS), Brazil
}

*Corresponding author: Caroline Borges Agustini, Department of Chemical Engineering, Laboratory for Leather and Environmental Studies (LACOURO), Federal University of Rio Grande doSul (UFRGS), Porto Alegre/RS, Brazil

Submission: 海 February 12, 2018; Published: 悳 February 22, 2018

\begin{abstract}
In the final stage of leather processing, many products are applied to form a protective coating. These coatings include resins such as polyacrylates, polyurethanes and casein. The composition of these materials was compared to physical-mechanical properties, as tensile strength resistance, elongation at break, toughness, hardness and thermal characterization by DSC and FTIR analysis. Tensile strength tests showed that the polyurethane resins, in general, have a higher tensile strength when compared to acrylic resins, as well as the values of toughness, indicating that these films support higher impact before the rupture of the material. The preparation of polymer-blend film had intermediate characteristics with respect to the pure components. Acrylic films tested had a higher elongation. With respect to hardness, the resins that were more flexible showed the lowest hardness. The characterization from FTIR and DSC analysis indicated the chemical groups and characteristic temperatures peaks of polyacrylates and polyurethanes.
\end{abstract}

Keywords: leather finishing, binders, polyacrylates, polyurethanes, caseins, tanning industry.

\section{Introduction}

The leather finishing comprises a set of treatment steps made at final stage in the process of leather manufacturing in tanneries and fills the important role of ensuring the final appearance and appropriate resistance properties in finished leather and leather goods. Depending on the article produced, specifications and characteristics related to physical- mechanical and chemical characteristics and minimization of environmental impacts by the leather finishing are required [1,2].

The principal requirement to formulate a leather finishing preparation is a composition of chemical with binder material properties to form a continuous film after drying. The products applied over the leather surface form a protective layer [3] which promotes the necessary resistance to leather and reach the technical specifications.

Polymer (binders or resins) based emulsions are widely used as coating materials for textiles, automotive paints, construction materials, leather, etc. [4,5]. In leather finishing, these resins are employed to produce films which protect the leather from mechanical damage, increase its stability when in contact with moisture and give the desired appearance, covering, color, brightness, texture and other visual and surface characteristics [6]. The resins are divided according to its application over the leather surface: the resins used for the base layers that can be combined with pigments and should be softer and more flexible and the resins used for the top layers that are responsible for physical properties $[7,8,9]$.The base layer is a soft layer applied in contact with the leather surface. Top layer is harder and applied over base layer.

The pre-combination of resins appears as an alternative to the existing binders, since the "polymer blends" assemble distinctive features according to the combined or mixed resins. Blends allow to reach a very special skill sets, because expand the range of specifications demanded by the leather goods and overcome technical limitation from each type of binder. Among the resins used in leather finishing, emphasis is given to casein, polyacrylates and polyurethanes [10-12]. A very wide range of polyurethane polymers are selected [13] and they are known to offer unique performance to surface coatings, such as high abrasion resistance, superior toughness, elastomeric properties, good chemical resistance, tensile strength, high extensibility at low temperature and properties that are simple to modify [14]. Polyacrylates are particularly noted for hardness, heat retention, gloss, light fastness [10] and high viscosity [15], they are available at economical cost and are therefore used more often [16].

Casein, which is a natural protein binder, promotes a transparent, higher brightness, vitreous, less plasticized and more natural film appearance $[14,17]$. Furthermore, due to their specific qualities including some restrictions involved in applying this material [18], caseins are used with combination to other binders 
for improvement of mechanical properties and water resistance. Modified casein is widely used as film binding component, and so it has a wide range of applications such as in papermaking, printing, coating, leather finishing and other fields [19]. The polyurethanes have the disadvantage of a high cost, but this can be substantially reduced by using acrylic and vinyl co monomers. Polyurethane dispersions offer similar performance compared to polyacrylates, but with higher toughness and durability [20]. Due to the environmental-friendliness, waterborne polyurethane (WPU) is widely studied as an important film-forming material [21,22].

New polymer films with various monomeric compositions (polymer blends including polyacrylates, polyurethanes, polybutadienes, etc.) and developments in application technologies and machines on the leather surface, receive attention for their importance on offer advantages compared to results from individual monomers [23-25]. Thermal properties [11,26-29] and physical-mechanical properties [4,7,10,30-32] of coatings applied on the leather surface are evaluated. Adhesion performance of various polymer types may be improved significantly by blending with other polymers [33-37].

Many authors analyze polymer binders by Fourier transform infrared spectroscopy (FTIR). FTIR analysis were used to study molecular structures of polymer blends composed of casein, polyurethane and acrylic dispersions application in base layer for leather finishing [6,19,26,27,38-41]. With differential scanning calorimetry (DSC) thermo- analytical technique, the difference in the amount of heat required for increase the temperature of a sample and reference is measured as a function of temperature. Authors $[6,26,27,41-44]$ studied the thermal stability of polyurethane and polyacrylates copolymers applied on the leather surface.
In general, studies evaluate physical-mechanical, thermal and performance properties of polymer films applied on leather surface. This study analyzed the purely polymer film from resins supplied from chemical companies to leather industry. The objective was to analyze chemical properties of pure and polymerblend commercial resins used to prepare different types of films, affording the fundamental scientific and technical knowledge. As the specific characteristics of each resin become known, technological improvements provide superior properties in finished leather products. Moreover, it is possible to combine resins to achieve better results with respect to leather product requirements.

\section{Materials and Experimental}

Polymer films were prepared from resins samples in Petri dishes to obtain emulsions with $30 \mathrm{~g}$ and $10 \%$ total solids. The physicalmechanical properties of the films were checked by measurements of hardness, tensile strength, elongation at break and toughness tests and were analyzed by Fourier transform infrared spectroscopy (FTIR) and differential scanning calorimetry (DSC).

\section{Materials}

The samples of polyurethane, acrylic resins and casein were provided by the Brazilian Units of the Companies TFL and Corium. These resins are commercial products prepared for application at top and base layer in the leather finishing. Casein produced films were too brittle, so it was not possible to prepare pure casein films. The influence of casein was studied only in combined films, by mixtures with polyurethane or acrylic resins. The resins that were used for the films preparation and characterization of their properties for leather finishing are presented in Table 1.

Table 1: Polyurethane, acrylic and casein resins selected for films preparation and polymer- blends composition.

\begin{tabular}{|c|c|c|c|c|c|}
\hline \multicolumn{3}{|c|}{ Polyurethane } & \multicolumn{3}{|r|}{ Acrylic } \\
\hline$\% \mathrm{ST}$ & & Nature/Use & $\%$ ST & & Nature/Use \\
\hline PU1 & 20 & Matt aliphatic PU dispersion/Top & Ac1 & 26 & Matt acrylic emulsion/Top \\
\hline PU2 & 17 & PU aqueous solution/Top & Ac2 & 25 & Glossy acrylic emulsion/Top \\
\hline PU3 & 15 & PU aqueous solution/Top & Ac3 & 35 & Aqueous acrylic emulsion/Base \\
\hline PU4 & 20 & $\begin{array}{l}\text { Medium-matt aliphatic PU } \\
\text { dispersion/Top }\end{array}$ & Ac4 & 35 & Acrylic polymer/Base \\
\hline \multirow[t]{2}{*}{ PU5 } & 16,5 & Modified matt PU/Top & \multicolumn{3}{|r|}{ Casein } \\
\hline & & & $\% \mathrm{ST}$ & & Nature/Use \\
\hline PU6 & 18 & Modified aliphatic PU (glossy)/Top & Cas1 & 10 & Medium hardness casein/Top or Base \\
\hline PU7 & 32 & Hard and glossy PU/Top & Cas2 & 15 & $\begin{array}{l}\text { Medium hardness casein with } \\
\text { polyamide/Top or Base }\end{array}$ \\
\hline
\end{tabular}




\begin{tabular}{|c|c|c|c|c|}
\hline PU8 & 20 & PU aqueous dispersion/Top & $50 / 50^{*}$ & $\begin{array}{c}\text { 8 Blends: (1) PU5 + PU8; (2) PU6 + PU9; (3) PU7 + } \\
\text { PU10; (4) Ac2 + Cas1; (5) Ac2 + PU8; (6) Ac2 + PU11; } \\
\text { (7) Ac3 + Ac4; (8) PU8 + Cas2 }\end{array}$ \\
\hline PU9 & 19 & PU aqueous dispersion/Top & $75 / 25^{*}$ & 3 Blends: (1) Ac2 + Cas2; (2) Ac2 + Cas1; (3) PU8 + \\
Cas1
\end{tabular}

\section{Film preparation}

A methodology for film building was developed establishing the final percentage of solids required. The solid content of the resin was calculated based on ABNT 11062 [45]-Determination of Total Solids and the film preparation was based on ABNT 11033 [46]Film Preparation. Pure films were prepared only with one type of resin and water, while polymer blend films were obtained from two or three resins and water.

For the preparation of films, the solids content in30g of suspension was set to $10 \%$ total solids (TS) in water. In Petri dishes of $120 \mathrm{~mm}$ diameter and $20 \mathrm{~mm}$ height, the resin was diluted with the water volume calculated until the amount of solids reached the dilution needed for obtaining the desired concentration. Equation (1) indicates the calculation of the quantity in grams of resin ( $x$ ) necessary to prepare the film. The water quantity is the difference $(30 \mathrm{~g}-\mathrm{x})$.

$$
\mathrm{x}=(10 \%) \times(30 \mathrm{~g})(\text { Eq. } 1)
$$

\section{(\%ST Resin)}

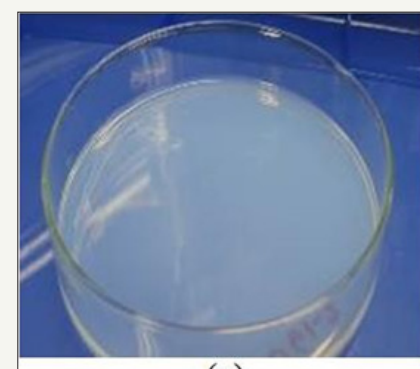

(a)

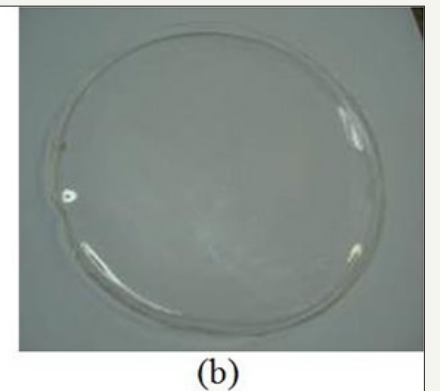

(b)

Figure 1 : (a) Petri dish with the suspension of water and PU11 resin before drying. (b) Polymeric film with PU11 resin after drying.

The films were prepared from combination of two or three resins in proportions of 50/50,75/25, 90/10, 75/20/5, 90/7/3 and $95 / 3 / 2$. The equation for polymer-blend films preparation (Resin 1+Resin 2) or (Resin 1+Resin 2+Resin 3) was the same as the one used for pure films. The Petri dishes were then placed in oven for $24 \mathrm{~h}$ at $60^{\circ} \mathrm{C}$ (Figure 1a) until the mixture was dried and the film was formed (Figure 1b). Figure 2 illustrates pure films prepared from acrylic and polyurethane resins.

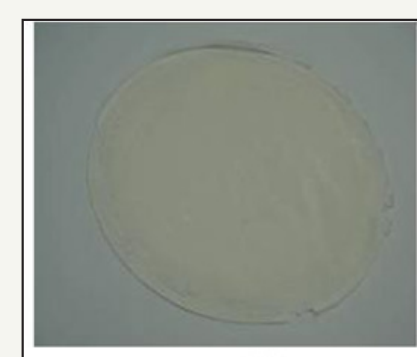

(a)

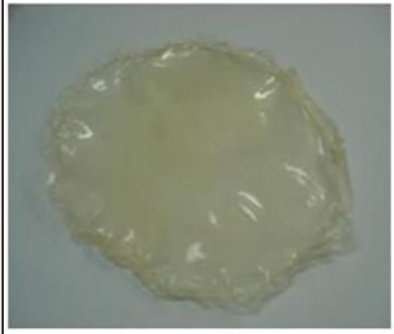

(c)

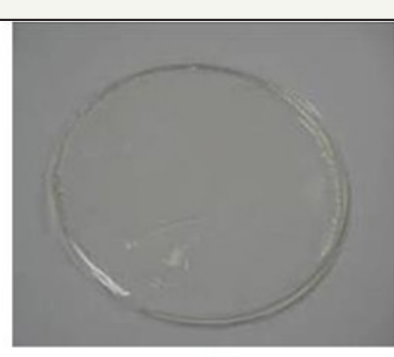

(b)

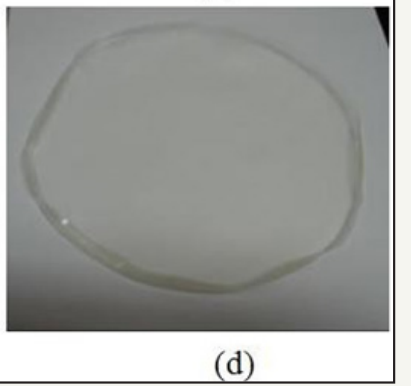

(d)
Figure 2 : Pure films prepared from resins after drying for $24 \mathrm{~h}$ at $60^{\circ} \mathrm{C}$ :

(a) Ac1, (b) Ac2, (c) PU3 and (d) PU5

\section{Analysis and characterization of the polymer films}

Hardness analysis: Hardness measurement was performed in accordance with ASTM D 2240 [47] - Standard Test Method for Determination of Hardness. The films had the thickness of $0.3 \mathrm{~mm}$ and they were cut in $2.5 \mathrm{~cm} \times 2.5 \mathrm{~cm}$ squares. So, that "test specimens" of films had the thickness of $0.3 \mathrm{~mm}$ and several of them had to be overlapped in order to attain the minimum height of $6.0 \mathrm{~mm}$ recommended in the standard. The tests were performed using a digital durometer-Shore A Woltest, model GS 709 with support for SD durometer Woltest 300. The procedure consisted of subjecting the material to a defined pressure applied using a calibrated spring acting on a conical indenter. Then, a device measured the depth of indentation. The hardness value was given by the penetration depth in the material under test, for an application time of 1 second.

Tensile strength, elongation and toughness of films: The tensile strength testing of the polymer films was performed according to ASTM D882 [48] tensile properties of thin plastic 
sheeting and ABNT NBR 11041 [49] leather physical and mechanical tests determination of tensile strength and percentage extension. Once the elongation of the material was larger than $100 \%$, the speed of the tensile strength machine was set to $500 \mathrm{~mm} / \mathrm{min}$, according to the standard procedure. It was considered appropriate to analyze the film in similar effort conditions to the mechanical tests performed on finished leather. In this way, a range of films with different resistances to stretching could be subjected to mechanical stress, presenting a response that was within the maximum elongation of the tensile strength machine used (AME $5 \mathrm{kN}$, Oswaldo Filizola, Brazil). Thus, the tests were performed in similar conditions for the results to be compared. The test specimen used for testing the films (Figure 3) was made by adapting the standards for leather testing: ASTM D638 [50] Standard Test Method for Tensile Properties of Plastics. The size of the sample had the length of the narrow section of the dumbbell sample from $4 \mathrm{~cm}$ to $2 \mathrm{~cm}$. The films were prepared in duplicate and, for each film, three specimens were cut for tensile tests (triplicate). Then, six specimens for each type of film were tested. The toughness measurements of the resins were calculated as the value of the integral relative to the area under stress-strain curves.

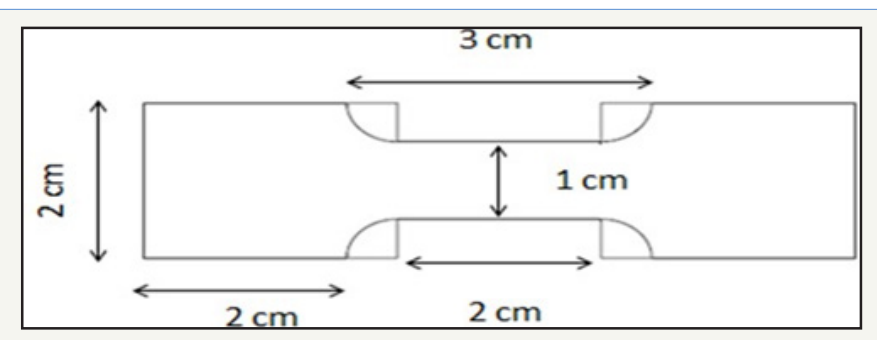

Figure 3: Template used for producing the specimens of the films for the tensile test.

The film samples were analyzed by Fourier Transform Infrared Spectroscopy (FTIR) (FTIR-ATR equipment from Bruker Alpha) in order to verify the chemical composition. The films were also characterized by differential scanning calorimetry in DSC Q20 equipment from TA Instruments. The samples were cut with a specific device and placed in Aluminium Hermetic brackets. The gas used was ultra pure nitrogen at a flow rate of $50 \mathrm{~mL} / \mathrm{min}$. The analysis began at a temperature of $-85^{\circ} \mathrm{C}$ with isotherm of 3 minutes. Two heating ramps with a cooling rate of $20^{\circ} \mathrm{C} / \mathrm{min}$ were used. The first heating ramp up to $200{ }^{\circ} \mathrm{C}$ was followed by an isotherm of 3 minutes. Then cooling was performed to $-85^{\circ} \mathrm{C}$ with an isotherm of 3 minutes and the second heating ramp went again up to $200{ }^{\circ} \mathrm{C}$. ASTM D3418 [51] standard specifies that the appropriate heating rate for the determination of $\mathrm{Tg}$ is $20^{\circ} \mathrm{C} / \mathrm{min}$.

\section{Results and discussion}

\section{Analysis of physical-mechanical properties}

Table 2 shows hardness values of some films prepared from polyurethane and acrylic resins. Polyurethanes and polyacrylates hardness didn't differ from each other. In general, base layer resins are softer and more flexible than top layer resins. The acrylic base layer resins Ac3 and Ac4 had the lowest hardness. In polyurethanes, this difference was not so evident, base and top layer resins showed high hardness, with PU10 and PU11 (base layer resins) harder than most of the PU top layer resins. From the tensile tests, the characteristic toughness values for each type of finishing product/ sample (Figure 4), the tensile strength resistance (Figure 5) and the percentage of elongation (Figure 6) were obtained. In the graphics, the films were grouped according to the nature of the resin (acrylic or polyurethane) and its use (top or base layer).The toughness values were calculated from the area under the stress-strain curve. These toughness values for polyurethane films were overall higher than the values for acrylics, so these films support greater impact before the material breaks. As Canevarolo [52] showed toughness and $\mathrm{Tg}$ are related. Polymers with higher molecular mobility show increased flexibility and consequently increased toughness.

Table 2: Hardness of pure films produced from resins used in leather finishing.

\begin{tabular}{|c|c|c|c|c|c|c|c|c|c|c|c|}
\hline Ac2 & Ac3 & Ac4 & PU2 & PU3 & PU4 & PU5 & PU7 & PU9 & PU10 & PU11 & \\
\hline & Top & Base & Base & Top & Top & Top & Top & Top & Тор & Base & Base \\
\hline $\begin{array}{l}\text { Hardness } \\
\text { (Shore A) }\end{array}$ & 59 & 23 & 30 & 41 & 52 & 47 & 46 & 82 & 73 & 71 & 69 \\
\hline
\end{tabular}

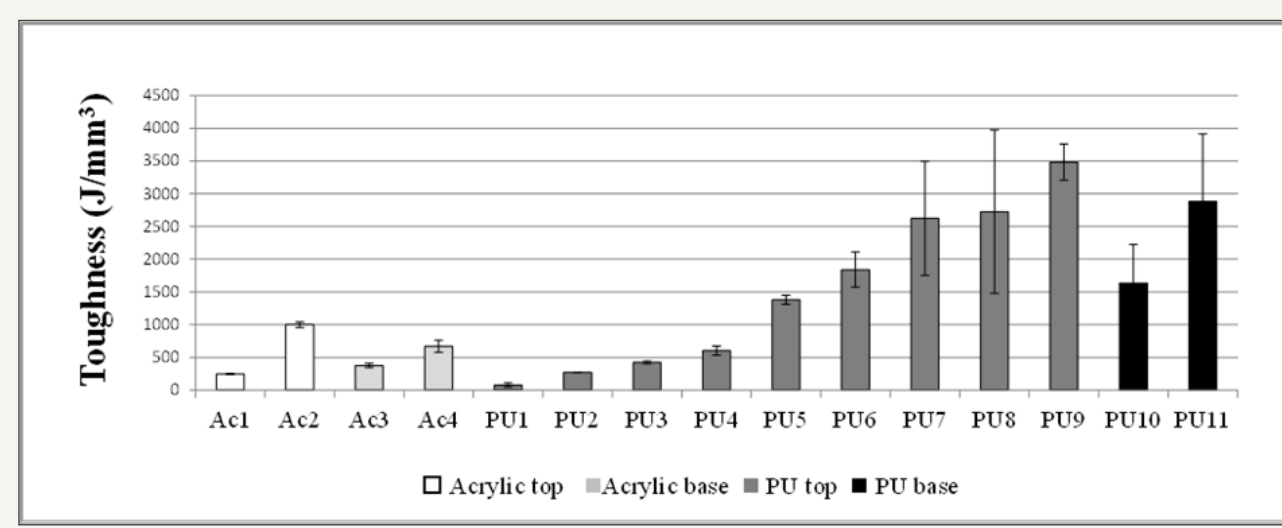

Figure 4 : Toughness of pure films prepared from resins used in leather finishing. 


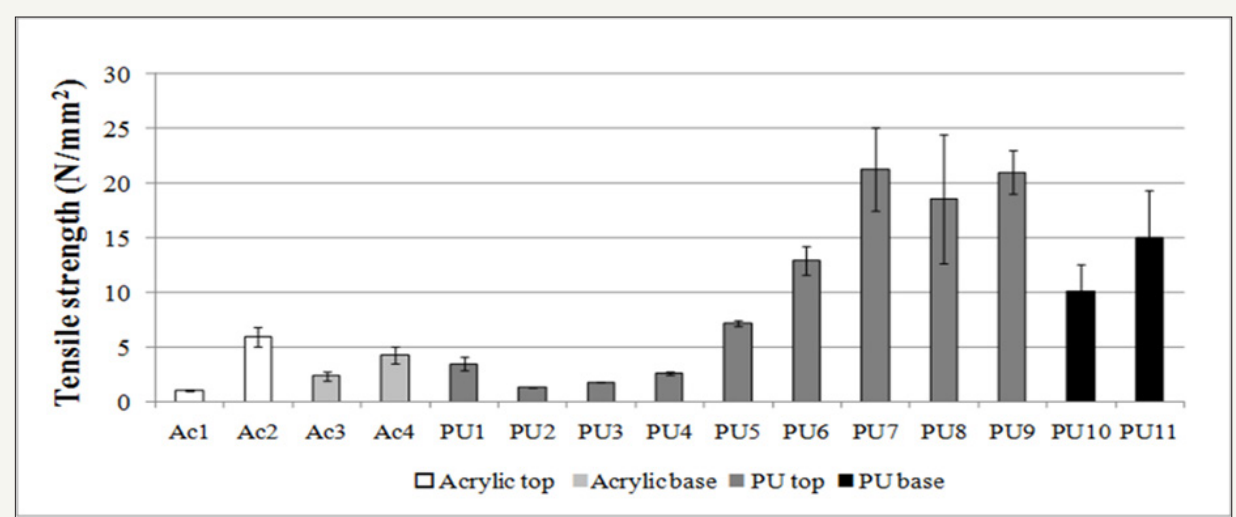

Figure 5 : Tensile strength of pure films prepared from resins used in leather finishing.

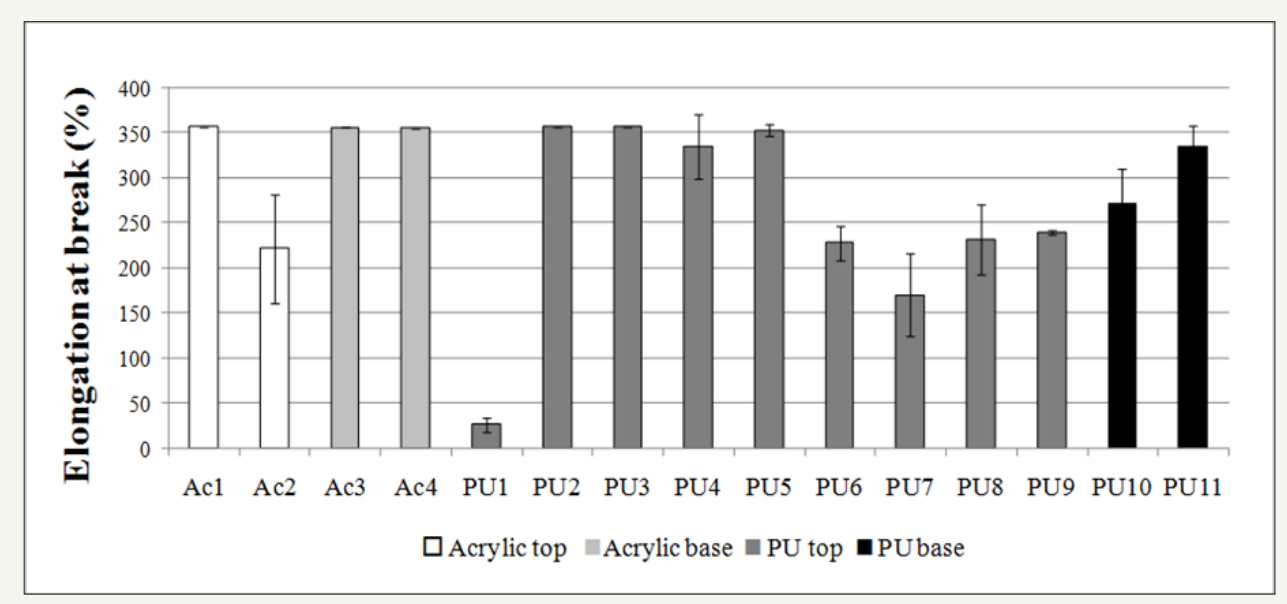

Figure 6 : Elongation of pure films from resins used in leather finishing subjected to tensile strength. Ac1, Ac3, Ac4, PU2, PU3 and PU5 exhibited elongation higher than 350\%.

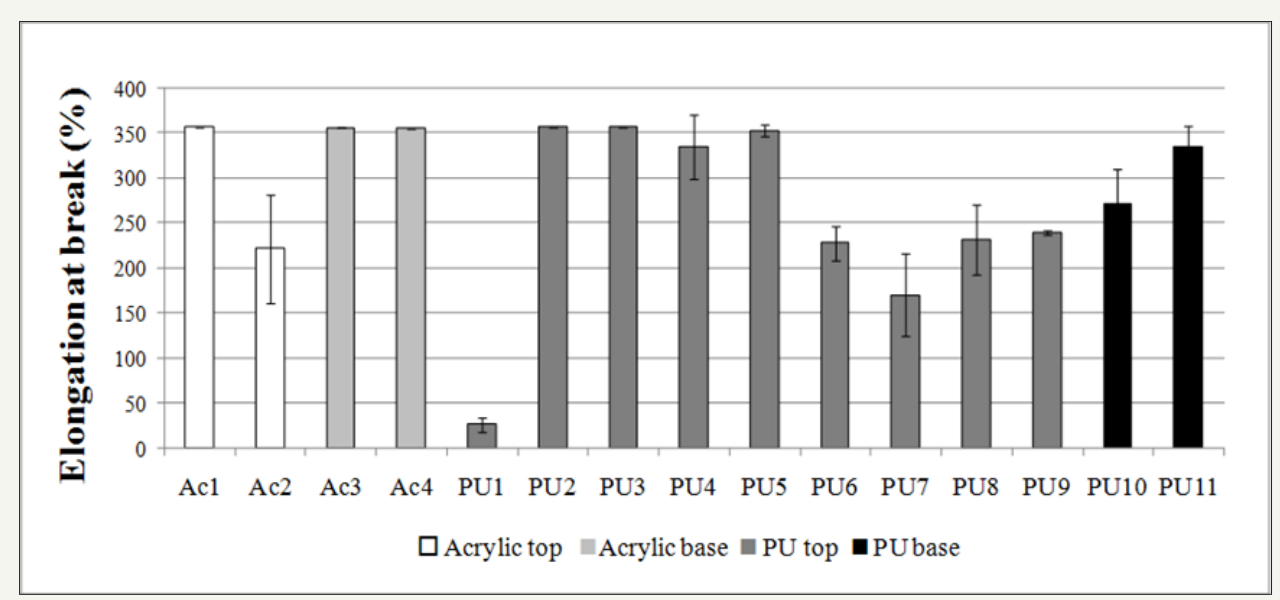

Figure 7 : Toughness of polymer-blend films produced from resins used in leather finishing.

With regard to tensile strength tests, the comparison among the polyurethane and acrylic resins didn't exhibit specific behavior for each film. According to their application as top or base layer, the types of resin didn`t show distinct difference and the tensile strength values were more representative in polyurethane samples (Figure 5). The elongation values (Figure 6) were higher in tests performed on acrylic films, because the most of films studied reached values above $350 \%$ (limit of the tensile machine), while for polyurethanes some films didn't reach the maximum elongation without rupture. The resins that had higher tensile strength value had lower elongation at break value (ex. PU7) compared to the resins rupturing under lower stress that had higher elongation values (ex. PU5), as observed when comparing Figures 5 \& 6. It was also compared the hardness values (Table 2) and the elongation 
(Figure 6), observing that more stretchy resins were, in general, less hardness, being softer and more flexible. It is important to note that the films analyzed were able to support sufficiently high stress, which can provide a wide range of resistant finishing films, especially in cases where finished leather has to be subjected to higher stress during its useful life. Resins with higher tensile strength give films with greater resistance and durability.

Polymer-blend films were prepared in order to analyze the influence on properties of each resin to final combined film. For films prepared from a mixture of resins, the properties were intermediate (ex. PU5-50/PU8-50) or superior (ex. PU7-50/ PU10-50) (Figure 7) to those of the respective films from pure resins (Figure 5). In relation to caseins, was observed a decrease in toughness, since casein forms a hard film, but brittle [53], which reduces the toughness of the film. Examples as Ac2/Cas2 and Ac2/Cas1 (at different ratios) polymer-blends (Figure 7) showed properties that were equivalent (ex. Ac-90/Cas-10) or lower (ex. Ac-75/Cas-25) than the pure film of Ac2 (Figure 4). It is interesting to note that for each different composition, toughness increases as the proportion of casein in the film decreases. The PU8/Cas1 blend was one of the cases in which the toughness increased. In addition, in the blend with PU8/Cas1/Ac2 all combinations of resins ratios showed increased toughness.
The comparative analysis of the rupture stress supported by the blend films when subjected to stress (Figure 8) in comparison to the pure films (Figure 5) showed intermediate values for blends, which was expected. Once more, the presence of casein in the combination of PU8-50/Cas2-50 resulted in decrease in tensile strength of the film with respect to the PU8 pure film. The addition of casein, both in the polyurethane and in the polyacrylate blends, led to a decrease in the rupture stress when the percentages of Cas1 and Cas 2 were higher than $10 \%$, but this tensile strength resistance increased in percentages up to $10 \%$. In blends containing PU8/ Cas1/Ac2, regardless of the ratio of resins used, the supported tensile strength also increased. The protein binders, such as casein, form hard, brittle and fragile films when dried, benefiting often from the addition of plasticizers [54].

The comparison among the elongation of blends (Figure 9) and pure films (Figure 6) showed, in general, intermediate values for films prepared from combinations of resins, and the same happened when there was a combination of three resins (Cas1/Pu8/Ac2). In films containing Cas1, all combinations showed an increase in the elongation of the specimen, the most pronounced increase being exhibited by the film containing $25 \%$ casein. For films containing Cas2, the elongation was reduced for films with $25 \%$ casein and showed increase in the case of the film with $10 \%$ casein.

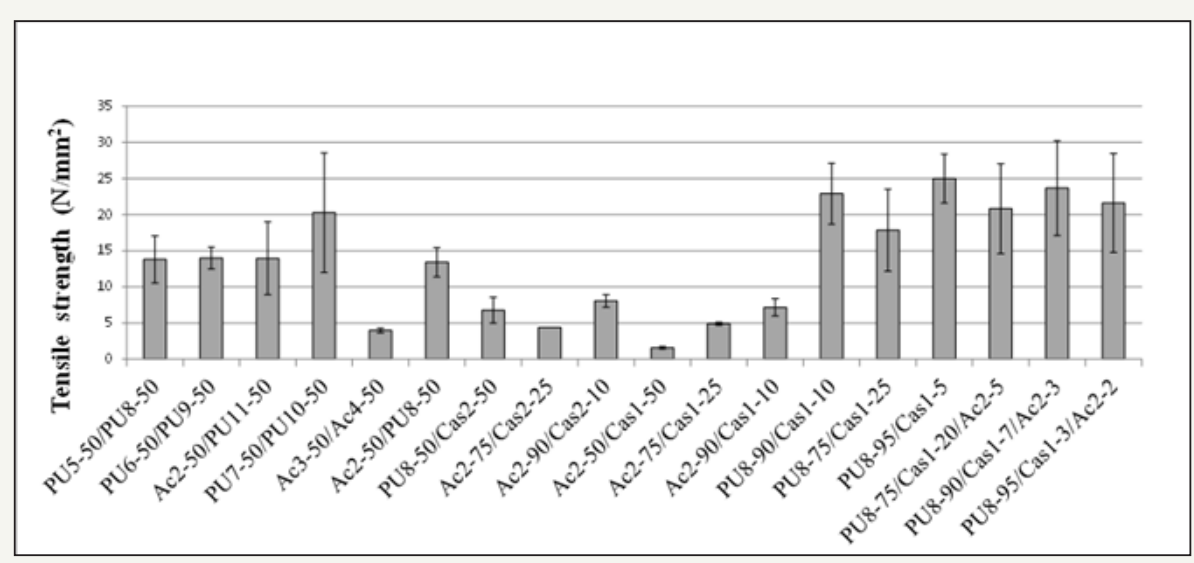

Figure 8 : Tensile strength of polymer blend films prepared from resins used in leather finishing.

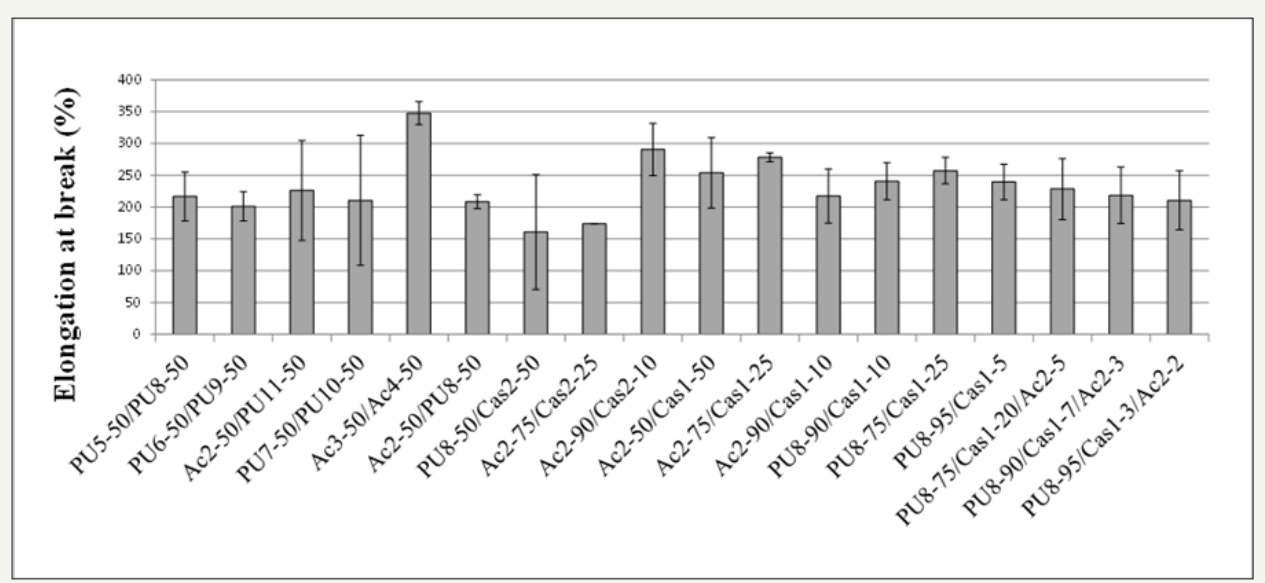

Figure 9 : Elongation at break of compact films prepared from resins used in leather finishing when subjected to tensile strength. 


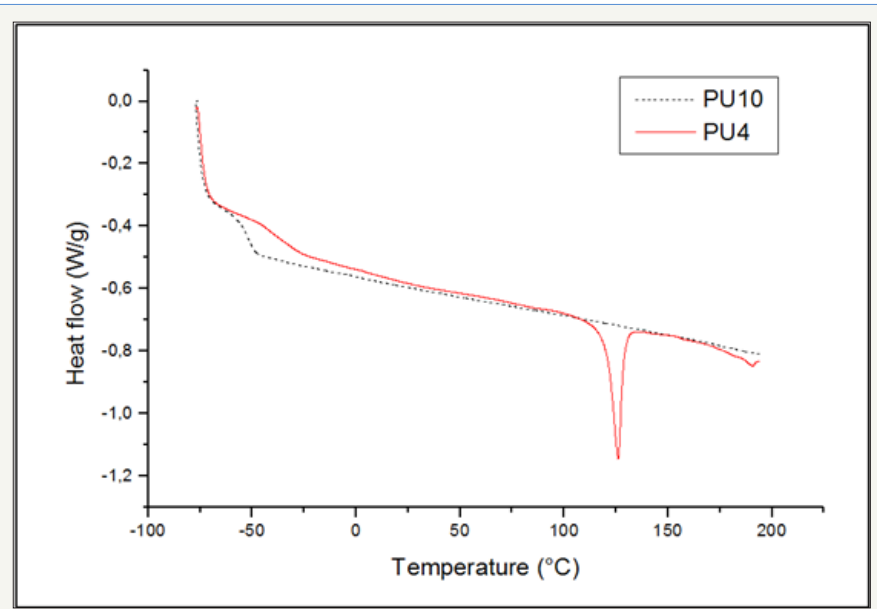

Figure 10 : DSC curves from the second heating ramp of PU10 and PU4 films.

\section{Thermal characterization of films prepared from resins used in leather finishing}

The films were characterized by FTIR and the thermal behavior was characterized using DSC. Figure 10 shows the curves of the second heating ramp for PU10 and PU4 resins. PU4 presented a peak probably associated to the melting temperature (Tm), whereas this was not observed for PU10, suggesting that the resin was completely amorphous. As the sample didn't show melting peak, this means that it had no crystallization peak either. The glass transition temperature (Tg) for the resin PU10 (base layer) was of about $-55^{\circ} \mathrm{C}$, while for PU4 (top layer) was at $-40{ }^{\circ} \mathrm{C}$. Base layer resins are typically softer than the top layer resins. The $\mathrm{Tg}$ of a polymer is related to its smoothness, the more negative its $\mathrm{Tg}$, the softer, or less hard will be the polymer. As showed by Agnelli [55], Tg range from -50 to $-30{ }^{\circ} \mathrm{C}$, depending on the urethane linkers or the physical blending.

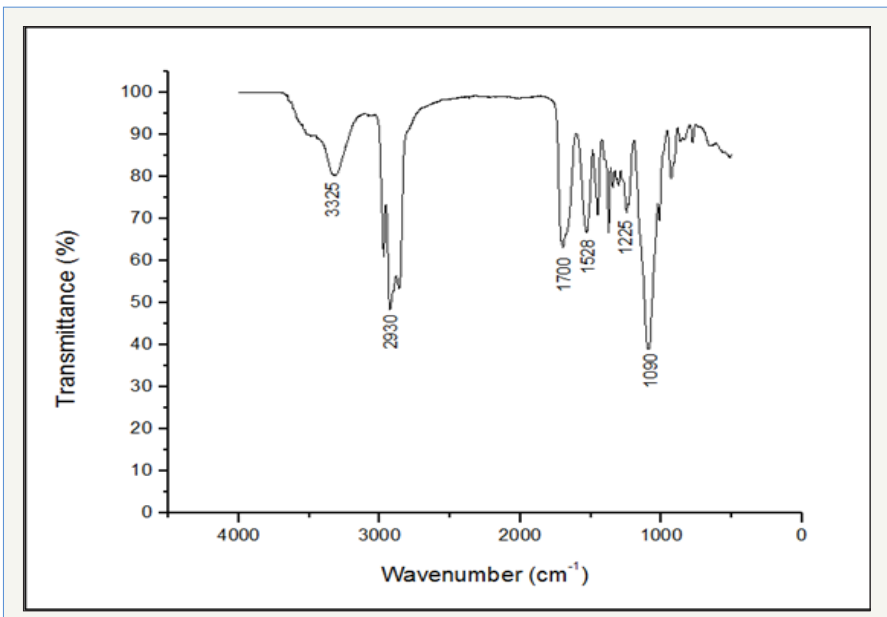

Figure 11 : FTIR spectrum of the PU10 film.

It is possible to access a characterization of polyurethane samples if DSC is used in combination with the infrared absorption spectra (Figure $11 \& 12$ ). By analyzing the infrared absorption spectra of the films of the two resins (Figure $11 \& 12$ ), it was observed the characteristic absorption peaks of polyurethanes according to literature data $[7,11,39,40,44,56]$. The peak at $3330 \mathrm{~cm}$ 1 is characteristic of the NH stretching band. The peak at $2928 \mathrm{~cm}^{-1}$ corresponds to the stretching vibrations of the aliphatic $\mathrm{CH}$ from $\mathrm{CH}_{2}$ or $\mathrm{CH}_{3}$ groups. The peak at $1700 \mathrm{~cm}^{-1}$ is the $\mathrm{C}=0$ stretching band and the one at $1100 \mathrm{~cm}^{-1}$ is characteristic for the backbone polyol (COC) or ether group. The spectrum shows the specific peaks of polyurethanes, but with the difference that the peak at $1700 \mathrm{~cm}^{-1}$ is much more intense in the PU4 spectrum. When comparing to the DSC analysis (Figure 10), it was noted that the PU4 sample had the most intense absorption peak at $1700 \mathrm{~cm}^{-1}$ and had a Tm peak, while the PU10 sample, with a lower absorption peak, had no Tm. The difference in the intensities of the peaks can be related to the thickness of the sample or to some grouping that is conferring a degree of crystallinity to the film. Still, it may be due also to the influence of some additive, as they are commonly used in finishing formulations.

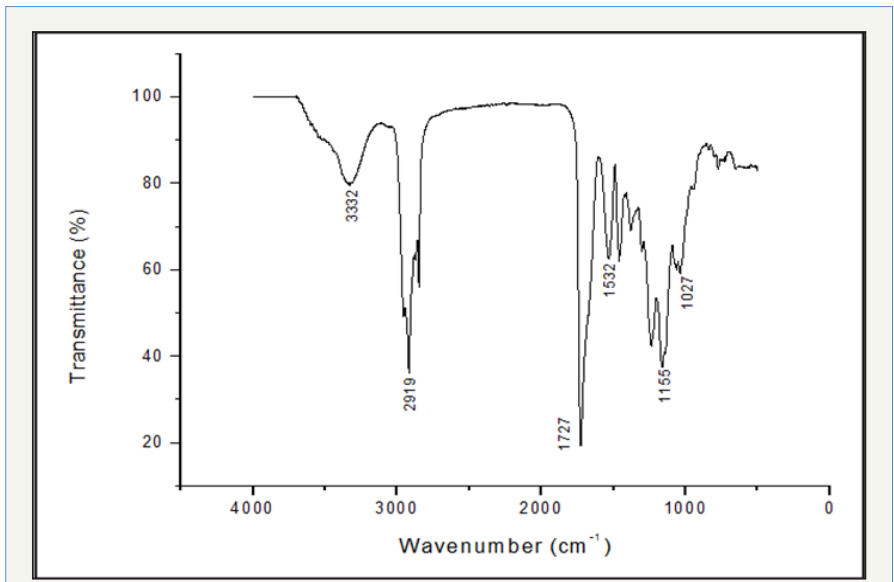

Figure 12 : FTIR spectrum of the PU4 film.

Regarding the polyacrylates, Figure 13 shows the very similar behavior of two acrylic films prepared from Ac3 and Ac4 resins. This result was in accordance with the other tests results in this study, which were similar for these two films. The Tg for these samples was approximately $-25^{\circ} \mathrm{C}$. The Tg value observed for these films corresponds to ethyl acrylate, according to reference values for different types of polyacrylates described in the literature [53,57-60].

The infrared absorption spectra for the Ac3 resin (Figure 14) and the Ac4 resin (Figure 15), also similar, showed the peaks as follows: the peak at $2975 \mathrm{~cm}^{-1}$ corresponds to the $\mathrm{CH}$ stretching vibrations of $\mathrm{CH}_{2}$. The peak at $1723 \mathrm{~cm}^{-1}$ corresponds to the $\mathrm{C}=0$ stretching band; the peak at $1440 \mathrm{~cm}^{-1}$ corresponds to the $\mathrm{CH}$ bending vibration of $\mathrm{CH}_{2}$; the peaks at $1240 \mathrm{~cm}^{-1}$ and $1150 \mathrm{~cm}^{-1}$ are due to the symmetric and asymmetric vibration of the $\mathrm{C}-\mathrm{O}$ bond, respectively. In both spectra, the peaks were identical, with small variations, indicating the same absorbance related to polyacrylates.

By analyzing the DSC curve for the Ac1 film (Figure 16) its $\mathrm{Tg}$ observed was $-52{ }^{\circ} \mathrm{C}$. Comparing to literature values [53,58,59], it is deduced that the resin is butyl acrylate, which has the same range of glass transition temperature. Since the resins are likely to 
have additives in their composition, these may interfere with the accurate Tg measurement or some other characteristics, such as viscosity, softness, etc. They may also consist of a physical mixture of acrylates or copolymers of acrylates with various monomers, thus differing from the homopolymers described in the literature.

In the FTIR spectrum (Figure 17), the absorption peak at $2940 \mathrm{~cm}^{-1}$ may be due to the asymmetrical vibration of $\mathrm{CH}_{3}$ in butylacrylate [61]. The absorption peak near $973 \mathrm{~cm}^{-1}$ is characteristic for butylacrylate [56].

\section{Conclusion}

Tensile strength, toughness and elongation showed differences between polyurethane and acrylic films. Tensile tests showed that the films from polyurethane resins, in general, have higher tensile strength resistance when compared with films from acrylic resins, as well as higher toughness values, indicating that these films can sustain a greater impact before the material breaks. In contrast, acrylic films tested had an increased ability to stretch. There wasn't a distinct difference in behavior between the films of base layer or top layer resins, showing variable behavior from the point of view of tensile strength, toughness and elongation. With respect to hardness, the resins that were more flexible and more stretching showed the lowest hardness. The addition of casein, in polyurethane and in polyacrylate blends, in general, reduced the toughness, tensile strength resistance and elongation, but in some combinations was observed an increase.

In order to achieve technological and innovative results and production requirements, in line with lower cost, the industry is constantly developing polymer-blends. This alternative combine individual characteristics, providing innovations that expand the possibilities for use and reach the widest possible range of application and specifications of these products. Blends showed, in general, intermediate values for the physical-mechanical characteristics tested when compared to pure films.

The characterizations by FTIR confirmed the specific absorption peaks of the characteristic chemical groups of polyacrylates and polyurethanes. They were complemented by the differential scanning calorimetry curves, indicating the glass transition temperatures of the studied material.

Resins used for the films preparation in leather finishing present a wide range of properties, so it is important a previous knowledge about these materials to obtain the best results in each purpose of use. This study emphasize that a resin is not better than other, but has its application more appropriate depending on the desired case.

\section{Acknowledgement}

Thanks to the scholarships provided by Brazilian Federal Agency for the Scholarship (CAPES) and Foundation for Research Support of the State of Rio Grande do Sul (FAPERGS) -public call 017/2012; and to the Brazilian Units of the Companies TFL and Corium for the resins supply.

\section{References}

1. Basaran B, Nalbat S (2012) A study of the realistic strength of leather: True stress. Journal of the American Leather Chemists Association 107(10): 342-347.

2. Mano EB (1991) Polymers as Engineering Materials. ( $2^{\text {nd }}$ edn), Blücher.

3. Stahl RV (2005) Solvent Free Finish. Leather Magazine 179: 74.

4. Bunk JKG, Pospiech DU, Eichhorn KJ, Müller M, Werner C, et al. (2010) Studying the influence of chemical structure on the surface properties of polymer films. Colloid Surface A: Physicochemical and Engineering Aspects 362(1-3): 47-57.

5. Domenech SC, Soldi V, Córdova J, Ávila AOV (2004) Recycling of polyurethanes techniques and alternatives. Tecnicouro Magazine 196: 42.

6. Sundar S, Vijayalakshmi N, Gupta S, Rajaram R, RRadhakrishnan G (2006) Aqueous dispersions of polyurethane of polyurethane-polyvinyl pyridine cationomers and their application as binder in base coat for leather finishing. Progress in Organic Coatings 56(2-3): 178-184.

7. Bacardit A, Canals T, Cobos M, Shendryck A, Solé O, et al. (2009) Characterization and evaluation of four types of finish topcoats. Journal of the Society Leather Technologists Chemists 93(4): 130-139.

8. Dillard DA (2002) Adhesion science and engineering I - The mechanics of adhesion. ( $1^{\text {st }}$ edn), Elsevier.

9. Hammond R (1992) Polyurethanes in leather manufacture. Leather Magazine 88: 86.

10. Jianzhong M, Zhijie Z, Lingyun L, Jing H (2005) Application of acrylic resin coating agent modified by nano $\mathrm{SiO}_{2}$. Journal of the Society Leather Technologists Chemists 90: 188.

11. Peizhi L, Yiding S, Xiaowu Y, Ganghui L (2010) Preparation of cationic fluorinated polyurethane - micro-emulsion and its application in leather finishing. Journal of the Society Leather Technologists Chemists 94(6): 240-247.

12. Somanathan N, Subramanian V, Mandal AB (1997) Thermal stability of modified caseins. Thermochimica Acta 302(1-2): 47-52.

13. Ollé L, Bacardit A, Morera JM, Bartolí E, Argelich G (2007) Cross linked polymers for aqueous finishing. Binders cross linked with polyaziridine, Part I: Behaviour of polyurethane. Journal of the Society Leather Technologists Chemists 92: 96.

14. Bao Y, Jianzhon M, Liu J, Lu J (2013) Polyurethane/polyacrylate/ silica nanocomposite prepared by seeded emulsion polymerization and the properties of finished leather. Journal of the Society Leather Technologists Chemists 97: 238.

15. Eckert G (1992) Possibilities and limits of the production of solvent-free leather finishes. Leather Magazine 88: 89.

16. Fazano CATV (1995) Paints methods of control of paints and surfaces. $\left(1^{\text {st }}\right.$ edn $)$, Hemus.

17. Liu L, Liu Q Li J, Du GCK (2012) Characterization of gelatin and casein films modified by microbial transglutaminase and the application as coating agents in leather finishing. Journal of the Society Leather Technologists Chemists 107(1): 13-20.

18. Wang NG, Zhang LN, Lu YS, Du YM (2004) Properties of crosslinked casein/waterborne polyurethane composites. Journal of Applied Polymer Science 91(1): 332-338.

19. Jianzhong M, Qunna X, Danggae G, Jianhua Z, Jing Z (2012) Blend composites of caprolactam-modified casein and waterborne polyurethane for film-forming binder: Miscibility, morphology and properties. Polymer Degradation Stability 97(8): 1545-1552.

20. Hoefler J, Hageman B, Chung CJ, Smith R (2013) High performance acrylic 
polymer technology for use in leather finishing processes. Journal of the American Leather Chemists 108: 311.

21. Zhang JL, Wu DM, Yang DY, Qiu FX (2010) Environmentally friendly polyurethane composites: preparation, characterization and mechanical properties. Journal of Polymers and Environments 18(2): 128-134.

22. Heping X, Fengxian Q, Yingying W, Dongya Y, Wenling W, et al. (2011) Preparation, mechanical properties of waterborne polyurethane and crosslinked polyurethane- acrylate composite. Journal of Applied Polymer Science 124(2): 958-968.

23. Uddin MK, Khan MA, Idriss KM (1996) Development of polymer films and its application on leather surfaces. Journal of Applied Polymer Science 60(6): 887-895.

24. Nie L, Liu J, Zheng XJ, Tamg K (2009) Synthesis and characterization of collagen hydrolysate/poly (vinyl alcohol)/silica biodegradable ternary composite film. National Natural Science Foundation of China and Natural Science Research Plan of Henan Province pp. 1-5.

25. Huanhuan S, Yi C, Haojun F, Jun X, Bi S (2010) Thermo sensitive polyurethane film and finished leather with controllable water vapor permeability. Journal of Applied Polymer Science 117(3): 1820-1827.

26. Yilmaz 0 (2014) A hybrid polyacrylate/OMMT nanocomposite latex: Synthesis, characterization and its application as a coating binder. Progress in Organic Coating 77(1): 110-117.

27. Jing H, Jianzhong M, Weijun D (2008) Synthesis of alkali-soluble copolymer (butyl acrylate/acrylic acid) and its application in leather finishing agent. European Polymer Journal 44(8): 2695-2701.

28. Chen L, Shi H, Wu H, Xiang J (2010) Preparation and characterization of a novel fluorinated acrylate resin. Journal of Fluorine Chemistry 131(6): 731-737.

29. Haojun F, Ling L, Xinnian F, Bi S (2004) The water vapour permeability of leather finished by thermally-responsive polyurethane. Journal of the Society of Leather Technologists and Chemists 89(3): 121-125.

30. Costello BA, Luckham PF, Manimaaran S (1994) The viscoelastic properties of confined polymer layers. Colloids and Surfaces A: Physicochemical and Engineering Aspects 86: 291-293.

31. Mohamed OA, Moustafa AB, Mehawed MA, El-Sayed NH (2008) Styrene and butyl methacrylate copolymers and their application in leather finishing. Journal of Applied Polymer Science 111(3): 1488-1495.

32. Ho PS, Poons TW, Leu J (1994) Molecular structure and thermal/ mechanical properties of polymer thin films. Journal of Physics and Chemistry of Solids 55(10): 1115-1124.

33. Awaja F, Gilbert M, Kelly G, Fox B, Pigram PJ (2009) Adhesion of polymers Progress in Polymer Science 34(9): 948-968.

34. Jainsankar SN, Lakshminarayana Y, Radhakrishnan G (1997) Compatibility of poly (vinyl chloride-vinyl acetate)/ polyester-based polyurethane blends. Polymer International 43(4): 368-372.

35. Chai S, Zhang Z (2010) Comparison of finishing application for aliphatic polyurethane dispersions and polyurethane/polyacrylate composite emulsions. Journal of the American Leather Chemists Association 105: 41-50.

36. Krings L, Jimenez M, Oliveras M, Pont Pi JM (2010) Acrylic-urethane hybrid polymers: Materials with high potential in leather finishing. Journal of the American Leather Chemists Association 105: 388.

37. Thang K, Zhu B, Zheng X, Shelly DC (2009) Preparation and properties of polyurethane finishing agent using butylamine as chain-extension agent. Journal of the American Leather Chemists Association 104: 295.

38. Zuber M, Zia KM, Bhatti IA, Jamil T, Rehman F, et al. (2012) Modification of cellulosic fabric using polyvinil alcohol, part-II: Colorfastness properties. Carbohydrate Polymers 87(4): 2439-2446.
39. Vélez-Pagés T, Martín-Martínez JM (2005) Application of one-component primer to avoid the roughening of leather and increase its adhesion to polyurethane adhesive. International Journal of Adhesion and Adhesives 25(4): 320-328.

40. Carbonell-Blasco P, Martín-Martínez JM, Antoniac IV (2013) Synthesis and characterization of polyurethane sealants containing rosin intended for sealing defect in annulus for disc regeneration. International Journal of Adhesion and Adhesives 42: 11-20.

41. Yilmaz O, Cheaburu CN, Gülümser G, Vasile C (2011) Rheological behaviour of acrylate/montmorillonite nanocomposite latexes and their application in leather finishing as binders. Progress in Organic Coatings $70(1): 52-58$

42. Turi E (1997) Thermal characterization of polymeric materials Academic Press, USA.

43. Kaya I, Kamaci M (2012) Synthesis, optical, electrochemical and thermal stability properties of poly(azomethine-urethane)s. Progress in Organic Coatings 74(1): 204-214.

44. Jing H, Jianzhong M, Weijun D (2008) Properties of acrylic resin/nano$\mathrm{SiO} 2$ leather finishing agent prepared via emulsifier-free emulsion polymerization. Materials Letters 62(17-18): 2931-2934.

45. ABNT (2004) Determination of total solids content.

46. ABNT (2004) Preparation of binder film.

47. ASTM (2005) Standard test method for rubber property durometer hardness.

48. ASTM (2002) Standard test method for tensile properties of thin plastic sheeting.

49. ABNT (2012) Leather physical and mechanical tests - Determination of tensile strength and percentage of extension.

50. ASTM (2002a) Standard test method for tensile properties of plastics

51.ASTM (2008) Standard test method for transition temperatures of polymers by thermal analysis.

52. Canevarolo SV (2006) Polymer Science. (2 $2^{\text {nd }}$ edn). Artliber.

53. Adzet AJM, Ballester BJ, Gratacos ME (1985) Chemistry tanning technology. Editora Romanyà/Valls.

54. Gratacos E, Boleda J, Portavella M, Adzet JM, Lluch G (1962) Chemical technology of leather. Editora Romanyà/Valls.

55. Agnelli JAM (1997) Characterization of polymers by non-infrared spectroscopy. In: $4^{\circ}$ Brazilian congress of polymers, Bahia. Apostila ABPOL - Associação brasileira de polímeros.

56. Hao L, An Q Xu W, Huang L (2012) Synthesis, film morphology and hidrophobicity of novel fluorinated polyacrylate emulsion and solution on silicon wafer. Colloids and Surfaces A: Physicochemical and Engineering Aspects 396: 83-89.

57. Lengyel I (1979) Macromolecules in Finishing. In: IV National Meeting of Chemicals and Technicians of the Leather Industry, Rio de Janeiro, Brazil.

58. Wunderlich B (2005) Thermal Analysis of Polymeric Materials. ( $1^{\text {st }}$ edn), Springer, USA

59. BASF (2004) Curriculum vademecum of the Tanner. ( $4^{\text {th }}$ edn), revised and extended.

60. Brydson JA (1999) Plastic materials. ( $7^{\text {th }}$ edn). Butterworth Heinemann.

61. Yilmaz 0, Cheaburu CN, Durraccio D, Gülümser G, Vasile C (2010) Preparation of stable acrylate/montmorillonite nanocomposite latex via in situ batch emulsion polymerization: Effect of clay types. Applied Clay Science 49(3): 288-297. 

(c) (i) Creative Commons Attribution 4.0

For possible submissions Click Here
Your subsequent submission with Crimson Publishers

\section{will attain the below benefits}

- High-level peer review and editorial services

- Freely accessible online immediately upon publication

- Authors retain the copyright to their work

- Licensing it under a Creative Commons license

- Visibility through different online platforms

- Global attainment for your research

- Article availability in different formats (Pdf, E-pub, Full Text)

- Endless customer service

- Reasonable Membership services

- Reprints availability upon request

- One step article tracking system 